\title{
RFID Based Warehouse Management of Perishable Products
}

\author{
Chandrakumar M. Badole ${ }^{1}$, Bimal Nepal ${ }^{2,}$ Ritu Agarwal ${ }^{3}$, A. P. S. Rathore ${ }^{1}$, \\ Rakesh Jain $^{1}$ \\ ${ }^{l}$ Mechanical Engineering Department, Malviya National Institute of Technology, Jaipur, India, 302017. \\ ${ }^{2}$ Industrial Distributions, Dwight Look College of Engineering, Texas A \& M University College \\ Station, TX 77843 \\ ${ }^{3}$ Institute of Engineering and Technology, JK Lakshmipat University, Jaipur, India, 302026
}

\begin{abstract}
The changing global market scenario, high level of competition, and faster obsolescence of perishable products due to short self life and changing customer demand are among the key challenges faced by perishable supply chains. Supply chains need to compete with growing variety of products, short delivery time, higher cycle service level, high quality and lower cost. Perishability imposes an intense pressure on managers as it adds an additional cost of disposal of outdated items, leading to out-of-stock situations and also loss of company faith. These problems are arising mostly due to the lack of information at every stage of the supply chains. The inadequate information about product quality, quantity, demand variability, product availability and lead times creates the bullwhip effect (BWE) at all stages and chains leads to the mismanagement.

RFID technologies, with the appropriate IT infrastructure, would help major distributors and manufacturers, as well as health-care system, defence industries, and global supply chains in which products and product shipments must be traced and identified in a non-contact, wireless fashion using a computer network. This paper presents the impact of RFID in warehouse management of perishable products. It provides mathematical framework to asses the benefits of RFID in warehouse management. It helps management in the variety of ways including improvement in receiving and shipping processes, reduction in cycle counting efforts, reduction in stock outs/excess inventory, decreased counterfeiting, decreased returns, and reduction in inventory loss due to shrinkage and obsolescence. A sensitivity analysis has been presented at the end of paper which shows the compound effect of RFID, reduction in lead time and lead time variability. In all scenarios inventory level is reduced by certain percentage by incorporating RFID.
\end{abstract}

Keywords - Supply chain management, Perishable product, Inventory, RFID, Warehouse.

\section{Introduction}

Due to rapid technological innovation and market demand for customised products, perishable supply chains need to improve continuously in order to reduce inventories, waste and costs for increased efficiency within the chain and in the market channel. To that end, continuous monitoring of perishable and other supplies is required in order to trace product quality, product wastage and safety standards throughout the supply chains. There are considerable supply variations due to seasonality of agricultural production, weather conditions and biological nature of products. This results in input variation and unpredictability. Maintaining logistics and production systems for rapid response to customer needs, higher product level variability, and market fragmentation are some of the other challenges facing perishable supply chains [1]. For perishable products, there is continuous change in quality from the production till consumption. This is a major challenge to face customer's quality requirement. Spoilage is another big problem of perishable products and it is caused principally due to excess stock and flawed stock rotation. Effective stock rotation ensures that products are taken from the storage in the correct order as determined by their sell-by dates. To overcome this problem, an effective information system is required.

The above-mentioned challenges are mostly the result of lack of information at every stage of the supply chains. The inadequate information about product quality, quantity, demand variability, product availability and lead times creates the bullwhip effect (BWE) at all stages and chains leads to the mismanagement. The BWE gets magnified from lower levels to higher levels of supply chains and also from local supply chains to global supply chains. Bullwhip effect is one of the most widely investigated phenomena in the modern day supply chain management research. It is the tendency to see an increase in variability in the replenishment orders with respect to true demand due to distortion in the demand information as we move upstream in the supply chain [2]. Also the researches [3-6] have found out that in supply chain lead time is the important factor for decision making. The managers must try to control lead time and lead time variability to reduce inventory while maintaining enough stocks to satisfy customer demand. This is equally important for the supply management of perishable product to reduce loss due spoilage and to provide fresh products to the customer with optimum cycle service level. It has been suggested that for cycle service levels above $50 \%$ the 
normal approximation predicts that a manager can reduce safety stocks by decreasing lead time uncertainty [3]. Companies such as Wal-Mart and Dell have gained efficiencies by having a clear understanding of customer value proposition and a tight commitment to predetermined delivery schedule. Information systems are the backbone of every supply chain and they are based on automatic data acquisition techniques to meet the goal of collecting information. Radio Frequency Identification (RFID) technology with unique characteristics can make it suitable to enhance data collection processes along the supply chain.

RFID is an automatic identification and data capture technology which is composed of three elements: a tag formed by a chip connected with an antenna; a reader that emits radio signals and receives in return answers from tags and finally a middleware that bridges RFID hardware and enterprise applications [7]. RFID technologies with the appropriate IT infrastructure would help both major distributors and manufacturers, as well as, other logistics operations, such as the health-care system, defence industries, and the systems dealing with complex, global supply chains in which products and product shipments must be traced and identified in a non-contact, wireless fashion using a computer network as perishable items are subjected to degradation $[\mathbf{8 , 9}$ ]. All of these requirements point to an automated wireless, readable sensory-based identification method, and network, that offers more functionalities and is significantly valuable than the existing methods. RFID has the potential to change the way we do business all around the world [11]. It is a huge challenge, not just because of the sophisticated sensor-network technology, but also because of the vast systems integration and coordination. RFID technology can increase a company's efficiency and provide other benefits to both companies and consumers; however, like any newly implemented technology, it presents management with issues of new system threats and decisions about incorporating adequate controls over the new technology [12]. The application fields and opportunities for RFID are vast. The key driver is that even in chaotic, largely distributed, more stochastic than deterministic business environments, adaptive organizations and enterprises must react to demands quickly, else a competitor will take the business. Therefore, they must reduce waste and improve efficiency at all fronts. The most important aspect of this strategy is to know exactly what parts they have in stock, exactly where these parts are, and in what condition/state of assembly, or preparedness [13]. Furthermore, major distributors dealing with complex, global supply chains must be able to trace their shipments in detail, either because of cost, security, safety, quality degradation (as it is in the case of temperature, humidity and/or shock sensitive components or drugs) and other reasons.

While the improved information accuracy through RFID deployment will allow companies to substantially reduce out-of-stocks and back orders, they are also likely to find themselves with higher overall average inventory. This suggests a remarkable improvement opportunity, namely that companies can potentially reduce reorder quantities and target inventory levels without hurting customer service levels. This opportunity to reduce inventory and at the same time, improve customer service levels can be applied not only across multiple tiers in the supply chain, but also within a single store (backroom and on-shelf replenishment). For example, accurately knowing the on-shelf inventory of products will enable replenishment of the shelf stock in an ondemand manner, thereby allowing the company to reduce the overall average store inventory without sacrificing product availability to customers.

The remaining part of this paper is organized as follows: Section 2 highlights the review of the past work done in this context. Section 3 presents the RFID based supply chain architecture along with the benefits of FID for supply chain. In section 4, we present the mathematical formulation to justify benefits of RFID in supply chain. Section 5 presents results and discussion. Conclusion and future scope is presented in the Section 6.

\section{Review Of Literature}

In the early stage of research work, a comprehensive literature review was carried out considering 302 research papers from about 40 reputed international journals, conference proceedings, research thesis and national conferences. The supply chain modelling based literature was only considered for reviews that were sourced from science direct, IEEE explore, Spingerlink, Google scholar etc. The out come of the review is that the research on adoption of new technology like RFID in controlling the supply chains of perishable products is scare and in the preliminary stage. Very few researchers have contributed in this region of supply chain management and the beneficial impacts of this technology have not been quantified mathematically and fruitfully. The researchers are found to have assumed the benefits in certain percentage using different notations.

The focus of researcher on the supply chain of perishable product started form 1950 onwards. The important early contributors were Ghere and Shrader [14], Covert and Philip [15] and Shah [16], who modelled economic order quantity for perishable inventory. Dave and Patel [17] have developed an inventory model with deterministic but linearly changing demand rate, constant deterioration rate and finite planning horizon. Whereas, Sachan [18] has extended the work of Dave and Patel [17] to allow for shortages. Datta and Pal [19] have presented an EOQ model considering variables deterioration and power demand pattern. Research work on modelling with deteriorating items, time-varying demand and shortages continues with a great dynamism and 
provide the new dimensions to supply chains studies [20,21]. The common characteristic of all the above papers is that they allow for shortages while unsatisfied demand is completely backlogged [22]. Most of the research work is concentrated on EOQ, replenishment and supply chain costs [23].

In the beginning of the twentieth century the trend has been found changed and the researchers are found inclined towards modelling the pricing strategies. The concept of a dynamic pricing was introduced to account for loss of inventory due to obsolescence. In this strategy, the researchers suggest that the price of the product be reduced as the self life, quality of product degrades day by day $[24,25]$. This strategy stood helpful in boosting demand for products and better generation of revenue which could have been lost in spoilage and loss of goodwill of company. The work was concentred on issuing policy of retail store where customers are found to prefer last in first out (LIFO) rather than first in first out (FIFO) policy [1]. This justifies the quality consciousness of today's customers. In such situations, the inventory loss can only be reduced by managing and maintaining adequate quantity of perishable products and is only possible by having the right time information about inventory at various stages and accordingly replenishing it from time to time. The newly emerging RFID technology is found to be a better solution to overcome problem [13].

Ranky [26] introduced the RFID with constructional details in their research. Basically the system consists of tag, antenna, sensor and software required for computational work. Jones et al. [27] and Bottani et al.[28, 29] explored the impacts and benefits of RFID on SC. They also studied the impact of RFID for retailers, assembly automations, grocery retailing, FMCG supply chains, in getting clearances in cargo yards and managing shipment in the yards. Tzeng, Chen and Pai [30] and Lee and Lee [31] carried out research on economical assessment of investment and benefits of RFID in supply chains. Hsu et al. [32] and Kok et al. [33] have carried out breakeven analysis for adoption of RFID in the business organization and cargo clearance process. Wu, Lin and $\mathrm{Yu}$ [34] explored the challenges to implement the RFID technology in an organization. Implementation of RFID is subjected to risks and needs to follow certain protocols, rules and regulations [35, 36]. Work carried out by Flores, Tanner and Amos [37] and Jedermann and Lang [38] adds value to the importance of RFID which can be effectively used in cold chains to increase self life of product and hence maintain quality for long time. Next section describes the difficulties/challenges faced by the perishable product supply chains.

\section{Rfid Based Supply Chain Architecture}

To understand the utility of RFID in the supply chain we developed RFID based supply chain architecture as shown in the figure below. It provides information about material and information flow throughout the supply chain using RFID database. All the stages are interconnected to each other using RFID database, hence any stage can avail all pertinent information about demand, order quantity, age and quality of product, delay and order status at any stage. This information (PoS data) can be used for planning and strategically decision making. Thus demand uncertainty at every stage may be reduced to a great extent.

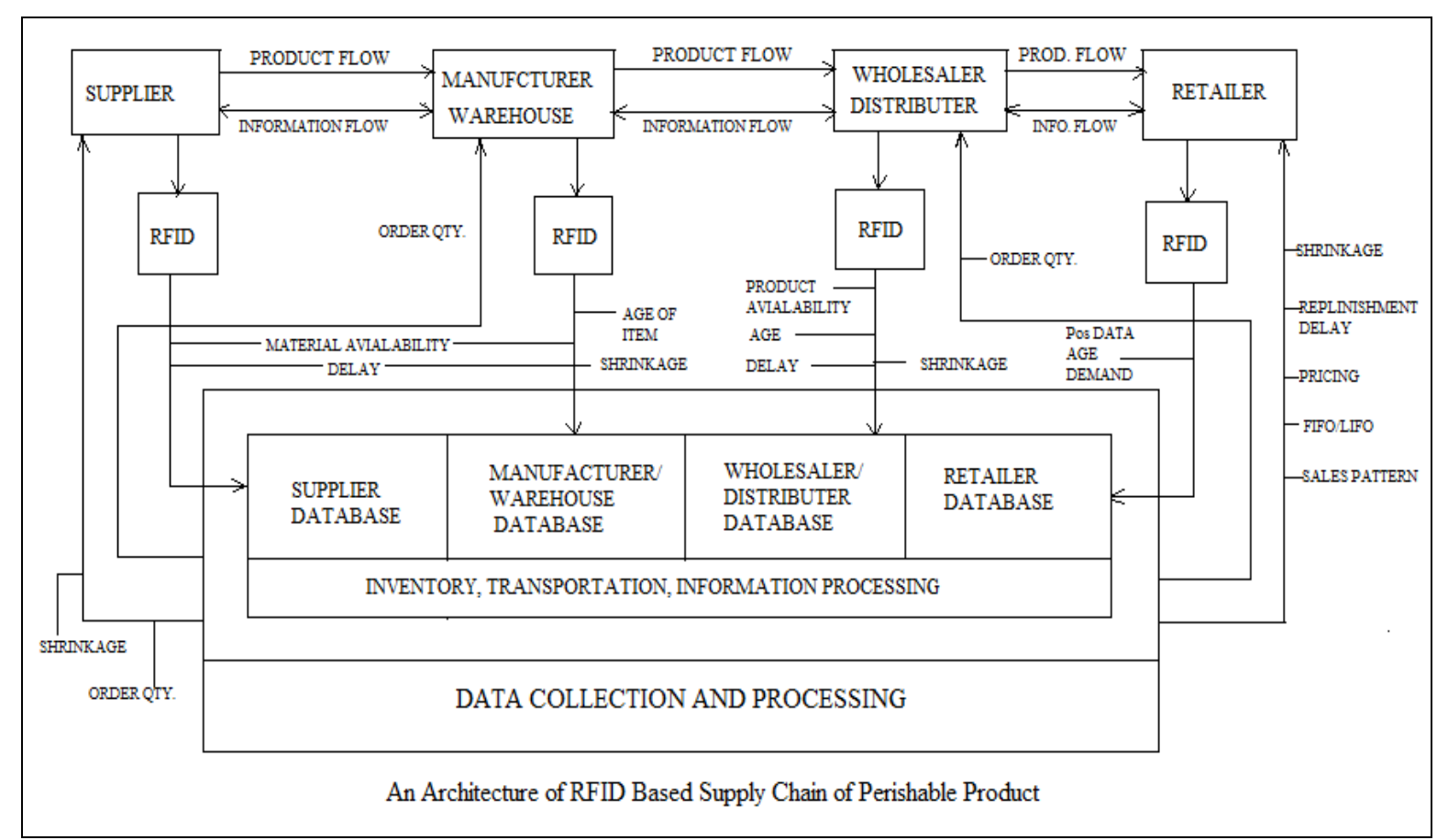

Figure 1: RFID based supply chain architecture 
The reduced uncertainty leads to the better management of inventory, reduced order quantity, reduced (optimum) safety stock in supply chain, reduced shrinkage, reduced stock outs, reduced loss due to counterfeiting, and certainly leads to the reduced overall cost. Using RFID sensors the quality of the product can be judge and based on the remaining available self life of product the newer pricing strategies can be incorporated to reduce the loss due to obsolescence. Also based on the nature and purchasing habits of the customers the decision can be taken regarding FIFO and or LIFO strategy to be implemented. Figure 2 depicts most of the benefits of RFID incorporated in the supply chain system. Our future research work aims to quantify these benefits by mathematical modelling and test the results conducting case study.

Literature survey indicates that major numbers of researchers have devoted their efforts to evaluate benefit to retailers incorporating RFID in SC ob non perishable products. Our aim to evaluate benefits of RFID in higher echelons (warehouse) of perishable products supply chains which can be equally applied to major distribution centres as well. In a warehouse very complex nature of activities are carried out and inventory management is the major task to satisfy every retailer and the customers associated to them. To deliver product to a customer without_disturbing its quality is the major challenge of every warehouse and distribution centre management. Another challenge is to reduce loss due to spoilage to reduce overall cost of supply chains.

Let us consider the simple form of supply chain consists of 4 echelons as shown figure below. Our focus is on warehouse activities with intention to evaluate the impact of RFID on various warehouse activities.

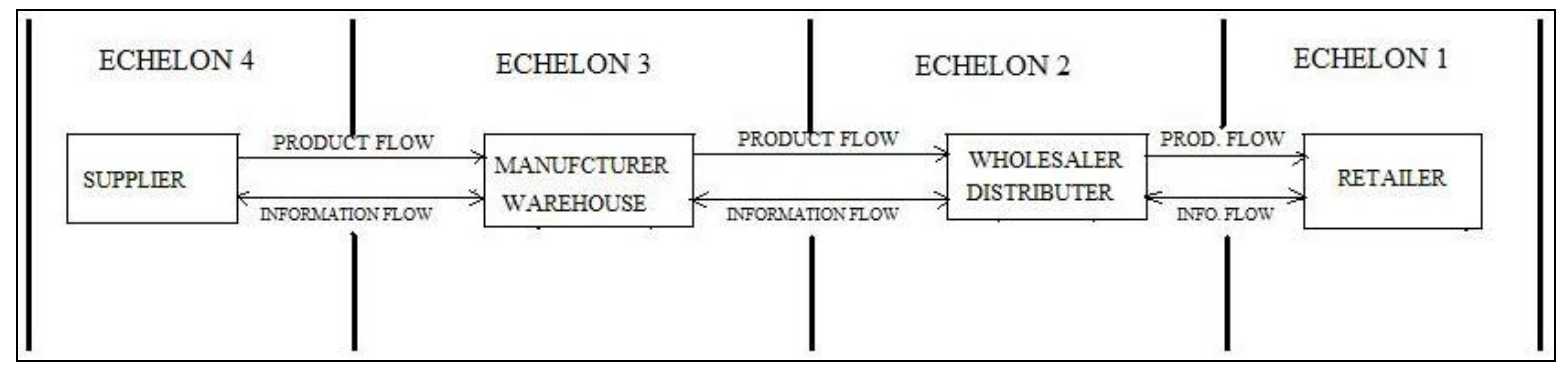

Figure 2: Simple form of supply chain with 4 echelons

At both manufacturing and distribution facilities (warehouses), there is a significant number of opportunities to improve operational efficiencies through the use of RFID, resulting in higher throughput, reduced inventory levels, improved visibility of incoming consignments, and improved follow up of orders, among many other benefits. The benefits of RFID in warehouse management are depicted in the figure below.

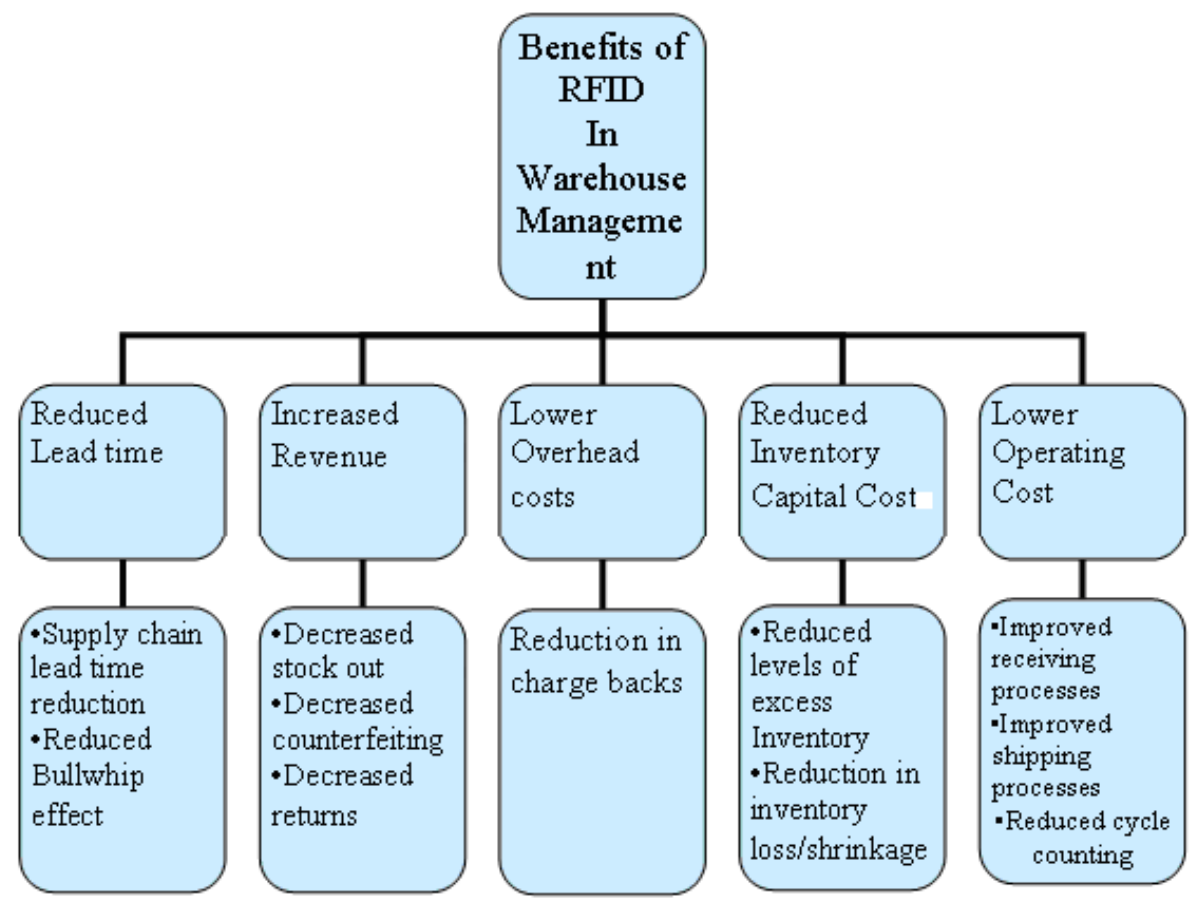

Figure 3: Benefits of RFID in warehouse management. 


\section{Mathematical Formulation/ Modelling}

In the following section the mathematical framework is provided to evaluate the benefits of RFID. In the ware house a cluster of complicated activities like receiving, unloading, for inbound and shipping, cross docking and loading for out bound operations are carried out as a routine work. By providing a mathematical frame work we tried to justify RFID benefits to certain important activities on micro level. Due to complex nature of activities the notations are considered in the manner that the activity could be understood simply. The guideline of analysis methodology is considered from the work of Chaug-Ing Hsu et al. and A. G. Kok et al. [32, 33] where in, the authors have formulated the various costs with and without the RFID. For formulations following assumptions and notations are considered:

\section{Assumptions}

1. That the RFID do not have any control on the rate of demand and hence demand rate has kept constant.

2. That in the complete analysis the echelon number ' $\mathrm{e}$ ' considered is $1, \ldots, 4$ and not repeated in the analysis all the way.

3. That the truck load type ' $\mathrm{t}$ ' is considered as $1, \ldots ., \mathrm{n}$ (any real number)

4. That the stock keeping unit SKU is considered as ' $i$ ' as 1 ,... m (any real number)

\section{Notations}

$e=$ echelon number, for $e=1, \ldots, 4$

$t=$ truck load type for $t=1 \ldots \ldots, \mathrm{n}$

$\mathrm{U}_{e t}=$ unloading time

$\mathrm{R}_{e t}=$ receiving time

$\mathrm{S}_{e t}=$ put away time

$\mathrm{J}_{e t}=$ picking time

$\mathrm{L}_{e t}=$ loading time

$\mathrm{IN}_{e t}=$ annual number of inbound truckloads

$\mathrm{OU}_{e t}=$ annual number of outbound truckloads

$\mathrm{GI}_{e t}=$ average work group size to work on an inbound truckload

$\mathrm{GO}_{e t}=$ average work group to work on an outbound truckload

$\eta \mathrm{IU}_{e t}=$ increased efficiency percentage for the unloading time after implementation of RFID

$\eta \mathrm{IR}_{e t}=$ increased efficiency percentage for the receiving time per unit after implementation of RFID

$\eta \mathrm{IS}_{e t}=$ increased efficiency percentage for the put away time per unit after implementation of RFID

$\eta \mathrm{IJ}_{e t}=$ increased efficiency percentage for the picking time per unit after implementation of RFID

$\eta \mathrm{IL}_{e t}=$ increased efficiency percentage for the loading time per unit after implementation of RFID

$\mathrm{GID}_{e t}=$ increased percentage of regular inbound units switched to cross docking

$\alpha \mathrm{I}_{e t}=$ inbound units per annum

$\alpha \mathrm{O}_{e t}=$ outbound units per annum

$\beta \mathrm{U}_{e t}=$ inbound units for cross docking

$\tau \mathrm{FI}_{e t}=$ fixed time per incoming truckload

$\tau \mathrm{FO}_{e t}=$ fixed time per outgoing truckload

$\theta_{e}=$ annual operating available hours

$\varphi \mathrm{I}_{e}=$ number of inbound dedicated dock doors

$\varphi \mathrm{O}_{e}=$ number of outbound dedicated dock doors

$\varsigma \mathrm{A}_{e}=$ effective annual available hours

$\lambda \mathrm{G}_{e}=$ average number of working groups

The warehouse process efficiency can be calculated as described below:

$\beta \mathrm{U}^{\prime}{ }_{e t}=$ new number of units for cross docking after RFID implementation

$\mathrm{U}^{\prime}{ }_{e t}=$ unloading time after implementation of RFID $=\mathrm{U}_{e t} *\left(1-\eta \mathrm{IU}_{e t}\right)$

$\mathrm{R}_{e t}^{\prime}=$ receiving time after implementation of RFID $=\operatorname{Ret} *\left(1-\eta \mathrm{R}_{e t}\right)$

$\mathrm{S}^{\prime}{ }_{e t}=$ put away time after implementation of RFID $=\mathrm{S}_{e t} *\left(1-\eta \mathrm{S}_{e t}\right)$

$\mathrm{J}_{e t}^{\prime}=$ picking time after implementation of RFID $=\mathrm{J}_{e t} *\left(1-\eta \mathrm{J}_{e t}\right)$

$\mathrm{L}_{e t}^{\prime}=$ loading time after implementation of RFID $=\mathrm{L}_{e t} *(1-\eta \mathrm{IL} e t)$

$\kappa \mathrm{I}_{e}=$ dock capacity inbound (Hours) $\quad=\Sigma \theta_{e} * \varphi \mathrm{I}_{e}$

$\kappa \mathrm{O}_{e}=$ dock capacity outbound (Hours) $=\Sigma \theta_{e} * \varphi \mathrm{O}_{e}$

$\kappa \mathrm{TI}_{e}=$ Total dock capacity(in Hours) of inbound and outbound $=\Sigma \kappa \mathrm{I}_{e}+\Sigma \kappa \mathrm{O}_{e}$

$\vartheta_{e}=$ labour capacity $=\Sigma \zeta \mathrm{A}_{e} * \lambda \mathrm{G}_{e}$ 


\subsection{DOCK AND LABOUR CAPACITY REDUCTION}

RFID is proved to be the most promising technology to change the way of doing business. It has great potential to improve every activity related to supply chain. In a warehouse a large clusters of activities are carried out on day to day basis. Every activity is associated the volume and amount of labour required to carryout that activity. In the following paragraphs we present the methodology to see how RFID can reduce total dock as well as labour capacity.

\subsubsection{EFFORTS AND CAPACITY UTILIZATION ANALYSIS}

Now, the labour hours and floor hours for inbound and out bound warehouse processes for echelon $\mathrm{e}=1, \ldots, 4$ and truck load $\mathrm{t}=1, \ldots \ldots, \mathrm{n}$ for current process is expressed as under:

$\Psi \mathrm{I}_{e t}=$ floor hours for inbound operations at current state

$=\tau \mathrm{FI}_{e t} * \mathrm{IN}_{e t}+\alpha \mathrm{I}_{e t}\left(\mathrm{U}_{e t}+\mathrm{R}_{e t}+\mathrm{S}_{e t}\right)-\beta \mathrm{U}_{e t} * \mathrm{~S}_{e t}$

$\Psi \mathrm{O}_{e t}=$ floor hours for outbound operations at current state

$=\tau \mathrm{FO}_{e t} * \mathrm{OU}_{e t}+\alpha \mathrm{O}_{e t}\left(\mathrm{~J}_{e t}+\mathrm{L}_{e t}\right)$

$\mathrm{LI}_{e t}=$ labour hours for inbound processes at current state $=\left(\alpha \mathrm{I}_{e t} *\left(\mathrm{U}_{e t}+\mathrm{R}_{e t}+\mathrm{S}_{e t}\right)-\beta \mathrm{U}_{e t} * \mathrm{~S}_{e t}\right) * \mathrm{GI}_{e t}$ $\mathrm{LO}_{e t}=$ labour hours for outbound processes at current state $=\left(\alpha \mathrm{O}_{e t} *\left(\mathrm{Jet}+\mathrm{L}_{e t}\right) * \mathrm{GO}_{e t}\right.$

Likewise, the labour hours and floor hours for inbound and out bound warehouse processes for echelon $\mathrm{e}=1, \ldots, 4$ and truck load $\mathrm{t}=1, \ldots . . \mathrm{n}$ for RFID enabled process is expressed as under:

$\Psi \mathrm{IR}_{e t}=$ floor hours for inbound operations after RFID implementation

$=\tau \mathrm{FI}_{e t} * \mathrm{IN}_{e t}+\alpha \mathrm{I}_{e t} *\left(\mathrm{U}_{e t}^{\prime}+\mathrm{R}_{e t}^{\prime}+\mathrm{S}_{e t}^{\prime}\right)-\left(\beta \mathrm{U}_{e t}^{\prime} * \mathrm{~S}_{e t}^{\prime}\right)$

$\Psi \mathrm{OR}_{e t}=$ floor hours for outbound operations after RFID implementation $=\tau \mathrm{FO}_{e t} * \mathrm{OU}_{e t}+\alpha \mathrm{O}_{e t} *\left(\mathrm{~J}^{\prime}{ }_{e t}+\mathrm{L}_{e t}^{\prime}\right)$

$\mathrm{LIR}_{e t}=$ labour hours for inbound processes after RFID implementation

$=\left(\alpha \mathrm{I}_{e t} *\left(\mathrm{U}_{e t}^{\prime}+\mathrm{R}_{e t}^{\prime}+\mathrm{S}_{e t}^{\prime}\right)-\beta \mathrm{U}_{e t}^{\prime} * \mathrm{~S}_{e t}^{\prime}\right) * \mathrm{GI}_{e t}$

$\mathrm{LOR}_{e t}=$ labour hours for outbound processes after RFID implementation $=\left(\alpha \mathrm{O}_{e t} *\left(\mathrm{~J}_{e t}^{\prime}+\mathrm{L}_{e t}^{\prime}\right)\right)^{*} \mathrm{GO}_{e t}$

To determine the dock capacity utilization and labour capacity utilization for the current process for echelon $\mathrm{e}=1, \ldots, 4$, following expressions can be used:

$\kappa \mathrm{U}_{e}=$ dock capacity utilization for inbound and outbound units at current state $=\Sigma\left(\Psi \mathrm{I}_{e}+\Psi \mathrm{O}_{e}\right) / \kappa \mathrm{TI}$

$\mathrm{LU}_{e}=$ labour capacity utilization at current state $=\left(\mathrm{LI}_{e}+\mathrm{LO}_{e}\right) / \vartheta_{e}$

Therefore, the gain in dock and labour capacity utilization using RFID can be calculated as under:

$\kappa \mathrm{UR}_{e}=$ dock capacity utilization for inbound and outbound units after RFID implementation

$=\Sigma\left(\Psi \mathrm{IR}_{e}+\Psi \mathrm{OR}\right)_{e} / \kappa \mathrm{TI}_{e}$

$\mathrm{LUR}_{e}=$ labour capacity utilization after RFID implementation $=\left(\mathrm{LIR}_{e}+\mathrm{LOR}_{e}\right) / \vartheta_{e}$

$\kappa \mathrm{AB}_{e}=$ dock capacity availability gain/benefit for inbound and outbound units $=\kappa \mathrm{U}_{e}-\kappa \mathrm{UR}_{e}$

$\mathrm{LAB}_{e}=$ labour capacity availability gain $=\mathrm{LU}_{e}-\mathrm{LUR}_{e}$

Using Eq. (5) and Eq. (6) dock and labour capacity utilization using RFID can be calculated which shows the benefit of RFID in the system.

\subsubsection{EFFICIENCY IMPROVEMENT IN CYCLE COUNTING}

Inventory accuracy can be improved to the great extent using RFID in the warehouse. This leads to reduction in excess, unsold and obsolete inventory, cycle counts reduction and decrease in orders. It will save time from the actual cycle count and also time laps to resolve the dispute over the discrepancy in cycle count between retailer and the warehouse. The notations used in cycle counting are expressed as under.

$I=$ SKU number, for $i=1, \ldots, \mathrm{n}$

$e=$ echelon number, for $e=1, \ldots, 4$

$\mathrm{T}_{i e}=$ time (in hours) it takes to complete one regular cycle count

$\mathrm{F}_{i e}=$ time (in hours) it takes to resolve one discrepancy cycle count

$\mathrm{W}_{i e}=$ hourly cost associated with the cycle counting employee

$\mathrm{N}_{i e}=$ number of discrepancies cycle counts conducted per annum at current state

$\mathrm{N}^{\prime}{ }_{i e}=$ number of discrepancies cycle counts conducted per annum after the implementation of RFID

Therefore, the cost of inventory inaccuracy if RFID was not incorporated can be evaluated as

Cost of Inventory Inaccuracy $=\Sigma\left(\mathrm{N}_{e}-\mathrm{N}_{e}^{\prime}\right) *\left(\mathrm{~F}_{e}-\mathrm{T}_{e}\right) * \mathrm{~W} e$

\subsection{INCREASE IN REVENUE}

The use of RFID in the system can increase revenue in many ways like reduced stock outs, reduction in counterfeiting incidents, reduction in charge backs, increased accuracy to locate defective items in the system, reduced inventory level, reduced in the inventory loss due to shrinkage, reduced requirement of warehouse space, reduced chances of expansion of warehouse $[9,12]$. Few of these ways are discussed in the succeeding paragraphs. 


\subsubsection{REDUCED STOCK OUTS}

A stock out occurs when the demand for item exceeds the inventory available at any instant. It's a result of many sources of errors in the organization like product unavailability at distribution centre, lack of inventory information at various stages. This situation becomes very harmful to the industry in the sense it can loose customer goodwill. The possibility of stock outs can be effectively reduced by incorporating RFID at the node points.

Let

$i=\mathrm{SKU}$ number, for $i=1, \ldots, \mathrm{n}$

$e=$ echelon number, for $e=1, \ldots, 4$

$\tau \mathrm{R}_{i e}=$ replenishment lead time

$\pi \mathrm{R}_{i e}=$ variance of replenishment lead time

$\rho \mathrm{D}_{i e}=$ variance of demand

$\mathfrak{f}_{i e}=$ inventory level accuracy

$\mathrm{QSO} \pi_{i e}=$ quantity of stock outs contributed by lead time variance

$\mathrm{QSO}_{i e}=$ quantity of stock outs contributed by demand variance

$\mathrm{QSO}_{i e}=$ quantity of stock outs contributed by inventory level accuracy

$\xi \tau \mathrm{R}_{i e}=$ percent of improvement in variability of replenishment lead time after implementation of RFID

$\xi \mathcal{E R}_{i e}=$ percent of improvement in variability of inventory level accuracy after implementation of RFID

$\mathrm{D}_{i e}=$ demand of items in units

$\mathrm{PS}_{i e}=$ selling price of SKU number

$\mathrm{QSO}_{i e}=$ stock out at the current level $=\left(\mathrm{QSO} \pi_{i e}+\mathrm{QSO}_{i e}+\mathrm{QSO}_{i e}\right)$

$\mathrm{QSOR}_{i e}=$ stock out after the implementation of RFID

$$
=\left(1-\xi \tau \mathrm{R}_{i e}\right) * \mathrm{QSO} \pi_{i e}+\mathrm{QSO} \rho_{i e}+\left(1-\xi £ \mathrm{R}_{i e}\right) * \mathrm{QSO} £_{i e}
$$

Therefore, from Eq. (8) and Eq. (9), confirm (increased) sell at any echelon e can be calculated as under $\mathrm{QRS}_{e}=$ realizable (increased) sales at echelon $e=\Sigma \mathrm{PS}_{i e} *\left(\mathrm{QSO}_{i e}-\mathrm{QSOR}_{i e}\right)$

Eq. (10) can be used in planning decisions regarding for order quantity, transportation, docking and promotions.

\subsubsection{REDUCED INCIDENTS OF COUNTERFEITING}

When wrong consignments of a particular products enters the warehouse, counterfeiting occurs, which can be a loss to the manufacturer. This issue can be very dangerous to particular product supply chains like pharmaceuticals and the food products [27]. One of the best way to reduce counterfeiting incidents the use of RFID in the system which restricts the entry of illegal and unauthorised items in he warehouse.

Let us consider

$i=\mathrm{SKU}$ number, for $i=1, \ldots, \mathrm{n}$

$e=$ echelon number, for $e=1, \ldots, 4$

$\lambda_{i e}=$ cost of counterfeited SKU

$\mathrm{QC}_{i e}=$ average number of counterfeited units of SKU

$\mathrm{Pc}_{i e}=$ percent of counterfeiting currently of SKU

$\mathrm{PcR}_{i e}=$ percent of counterfeiting after implementation of RFID

Therefore, the increased revenue due to reduced counterfeiting incidences is calculated as Increased revenue/ revenew saved due to reduced counterfeiting incidences

$\mathrm{RA}=\Sigma\left(\lambda_{i e} * \mathrm{QC}_{i e} *\left(\mathrm{Pc}_{i e}-\mathrm{PcR}_{i e}\right)\right)$ of $\mathrm{SKU}$

\subsubsection{EXCESS INVENTORY REDUCTION}

RFID based supply chain creates an opportunity to reduced costs that are involved in inventory. The on hand inventory level depends on many factors including lead times and its variability, consumer demand and its variability, money block in excess inventory and loss due to obsolescence [3-6]. The RFID can make improvement in lead time reduction, reduction in delivery lead time along with reduction in probability that the product become obsolete.

Let

$i=\mathrm{SKU}$ number, for $i=1, \ldots, \mathrm{n}$

$e=$ echelon number, for $t=1, \ldots, 4$

$\tau \mathrm{Mo}_{i e}=$ current lead time to move inventory from echelon (e +1$)$ start process to echelon (e)

$\pi \mathrm{Mo}_{i e}=$ current variance of lead time $\tau$ Moie

$\tau \mathrm{MoR}_{i e}=$ lead time after RFID implementation to move inventory from echelon $(\mathrm{e}+1)$ start process to echelon (e)

$\pi \mathrm{MoR}_{i e}=$ variance of lead time LTOie after RFID implementation

$\mathrm{D}_{i e}=$ demand of SKU 
$\rho \mathrm{D}_{i e}=$ variation of demand of SKU

$\mu=$ balancing risk factor of cost/benefit effects of inventory availability

Risk factor is considered to optimize the level of inventory availability

Then, Inventory Level is given by

$\mathrm{I}_{i e}=\left(\tau \mathrm{R}_{i e}+\pi \mathrm{R}_{i e} * \mu\right)\left(\mathrm{D}_{i e}+\rho \mathrm{D}_{i e} * \mu\right)$

As assumed earlier, the RFID do not control the demand related parameters, for mathematical formulation, all demand related parameters are consider constant (Kie)

$\mathrm{K}_{i e}=\left(\mathrm{D}_{i e}+\rho \mathrm{D}_{i e} * \mu\right)$

$\mathrm{I}_{i e}=\mathrm{K}_{i e} *\left(\tau \mathrm{Mo}_{i e}+\mu * \pi \mathrm{Mo}_{i e}\right)$ without RFID

$\mathrm{IR}_{i e}=\mathrm{K}_{i e} *\left(\tau \mathrm{MoR}_{i e}+\mu * \pi \mathrm{MoR}_{i e}\right)$ with RFID

Hence, the change in the level of excess inventory (reduced inventory) can be calculated using following expression

$\delta \mathrm{I}_{i e}=\mathrm{K}^{*}\left(\tau \mathrm{Mo}_{i e}+\tau \mathrm{MoR}_{i e}\right)+\mathrm{K}^{*} \mu^{*}\left(\pi \mathrm{Mo}_{i e}+\pi \mathrm{MoR}_{i e}\right)$

This equation can be directly used to calculate economical impact of RFID n supply chain as [28]:

Economic impact $=$ Reduced inventory level $*$ Holding cost.

In fact, the benefit of RFID is multi fold. The reduced excess level will lead to reduced loss of inventory due to obsolescence and will add in the revenue generation.

\subsubsection{REDUCED LOSS OF INVENTORY DUE TO OBSOLESCENCE/ SHRINKAGE}

Product availability greatly suffers due to loss of inventory due to obsolescence and shrinkage. Obsolescence is the wastage of product as its useful life (self life) becomes nil and the quality of product becomes useless. The product quality can be greatly monitored using RFID as the case of cold supply chains [36]. In such situations RFID becomes the powerful tool to monitor the temperature which governs the quality of product [37]. Also it provides guidelines to follow FIFO strategy to reduce obsolescence. However, the loss due to shrinkage is occurring because of theft, consumer or supplier. Bothe these concepts creates inventory inaccuracy which definitely can be corrected using RFID in the system. It reduces the work of correcting the inventory level calculations thus adding to the revenue generation.

Let,

$i=\mathrm{SKU}$ number, for $i=1, \ldots, \mathrm{n}$

$e=$ echelon number, for $t=1, \ldots, 4$

$\mathrm{qLS}_{i e}=$ units of inventory loss due to obsolescence/ shrinkage of SKU

$\mathrm{P}_{i e}=$ item cost of SKU

$\mathrm{qLSC}_{i e}=$ percent of inventory loss due to obsolescence/ shrinkage currently

$\mathrm{qLSR}_{i e}=$ percent of inventory loss due to obsolescence /shrinkage after implementation of RFID

Then, Cost saving due to reduced loss due to the obsolescence/shrinkage

$$
=\Sigma \mathrm{qLSC}_{i e} * \mathrm{P}_{i e} *\left(\mathrm{qLSC}_{i e}-\mathrm{qLSR}_{i e}\right)
$$

Eq. (11) provides information regarding the amount of money saved due to the reduced loss due to obsolescence or shrinkage as a part of implementation of RFID in the system.

\section{Sensitivity Analysis}

A sensitivity analysis is carried out for different values of $\mu$ to check its effect on inventory level reduction for four cases. The reduction in excess inventory level and its sensitivity analysis is presented in the following paragraph. We assume that Demand $=120$, lead time variances $=4,6,8$, and 10 . The sensitivity is carried out for the risk factor value $\mu=1,2$ and 3 and reduced lead time variance by $4 \%$ when RFID is used. The analysis shows the compound effect of RFID, reduction in lead time and lead time variability as shown in the following tables:

Table 1: Variation in inventory level for $\mu=3$

\begin{tabular}{|c|c|c|c|c|c|c|c|c|c|c|}
\hline \multirow[b]{2}{*}{ CASE } & \multirow[b]{2}{*}{$\mathrm{D}_{i e}$} & \multirow[b]{2}{*}{$\rho \mathrm{D}_{i e}$} & \multirow[b]{2}{*}{$\mathrm{K}_{i e}$} & \multicolumn{3}{|c|}{ without RFID } & \multicolumn{4}{|c|}{ With RFID } \\
\hline & & & & $\tau \mathrm{Mo}_{i e}$ & $\pi \mathrm{Mo}_{i e}$ & $\mathrm{I}_{i e}$ & $\begin{array}{l}\tau \mathrm{MoR}_{i e} \\
10 \% \text { less }\end{array}$ & $\begin{array}{l}\pi \mathrm{MoR}_{i e} \\
4 \% \text { less }\end{array}$ & $\mathrm{IR}_{i e}$ & $\begin{array}{c}\text { Reduced } \\
\text { Inventory } \\
\text { Level }\end{array}$ \\
\hline $\bar{A}$ & 120 & 10 & 150 & 40 & 4 & 7800 & 36 & 3.84 & 7128 & $8.62 \%$ \\
\hline $\mathrm{B}$ & 120 & 10 & 150 & 40 & 6 & 8700 & 36 & 5.76 & 7992 & $8.14 \%$ \\
\hline $\bar{C}$ & 120 & 10 & 150 & 25 & 8 & 7350 & 22.5 & 7.68 & 6831 & $7.06 \%$ \\
\hline $\bar{D}$ & 120 & 10 & $\overline{150}$ & 25 & 10 & 8250 & 22.5 & 9.6 & 7695 & $6.73 \%$ \\
\hline
\end{tabular}


Table 2: Variation in inventory level for $\mu=2$

\begin{tabular}{|c|c|c|c|c|c|c|c|c|c|c|}
\hline \multirow[b]{2}{*}{ CASE } & \multirow[b]{2}{*}{$\mathrm{D}_{i e}$} & \multirow[b]{2}{*}{$\rho \mathrm{D}_{i e}$} & \multirow[b]{2}{*}{$\mathrm{K}_{i e}$} & \multicolumn{3}{|c|}{ without RFID } & \multicolumn{4}{|c|}{ With RFID } \\
\hline & & & & $\tau \mathrm{Mo}_{i e}$ & $\pi \mathrm{Mo}_{i e}$ & $\mathrm{I}_{i e}$ & $\begin{array}{l}\mathrm{MoR}_{i e} \\
10 \% \text { less }\end{array}$ & $\begin{array}{l}\pi \mathrm{MoR}_{i e} \\
4 \% \text { less }\end{array}$ & $\mathrm{IR}_{i e}$ & $\begin{array}{c}\text { Reduced } \\
\text { Inventory } \\
\text { Level }\end{array}$ \\
\hline$\overline{\mathrm{A}}$ & 120 & 10 & $\overline{140}$ & 40 & 4 & 6720 & 36 & 3.84 & 6115.2 & $9.00 \%$ \\
\hline $\mathrm{B}$ & 120 & 10 & 140 & 40 & 6 & 7280 & 36 & 5.76 & 6652.8 & $8.62 \%$ \\
\hline $\bar{C}$ & 120 & 10 & 140 & 25 & 8 & 5740 & 22.5 & 7.68 & 5300.4 & $7.66 \%$ \\
\hline $\bar{D}$ & 120 & 10 & 140 & 25 & 10 & 6300 & 22.5 & 9.6 & 5838 & $7.33 \%$ \\
\hline
\end{tabular}

Table 3: Variation in inventory level for $\mu=1$

\begin{tabular}{|c|c|c|c|c|c|c|c|c|c|c|}
\hline \multirow{2}{*}{ CASE } & \multirow{2}{*}{$\mathrm{D}_{i e}$} & & & & \multicolumn{3}{|c|}{ without RFID } & \multicolumn{5}{|c|}{ With RFID } \\
\cline { 5 - 11 } & & $\mathrm{K}_{i e}$ & $\tau \mathrm{Mo}_{i e}$ & $\pi \mathrm{Mo}_{i e}$ & $\mathrm{I}_{i e}$ & $\begin{array}{c}\tau \mathrm{MoR}_{i e} \\
10 \% \text { less }\end{array}$ & $\begin{array}{c}\pi \mathrm{MoR}_{i e} \\
4 \% \text { less }\end{array}$ & $\mathrm{IR}_{i e}$ & $\begin{array}{c}\text { Reduced } \\
\text { Inventory } \\
\text { Level }\end{array}$ \\
\hline $\mathrm{A}$ & 120 & 10 & 130 & 40 & 4 & 5720 & 36 & 3.84 & 5179.2 & $9.45 \%$ \\
\hline $\mathrm{B}$ & 120 & 10 & 130 & 40 & 6 & 5980 & 36 & 5.76 & 5428.8 & $9.22 \%$ \\
\hline $\mathrm{C}$ & 120 & 10 & 130 & 25 & 8 & 4290 & 22.5 & 7.68 & 3923.4 & $8.55 \%$ \\
\hline $\mathrm{D}$ & 120 & 10 & 130 & 25 & 10 & 4550 & 22.5 & 9.6 & 4173 & $8.29 \%$ \\
\hline
\end{tabular}

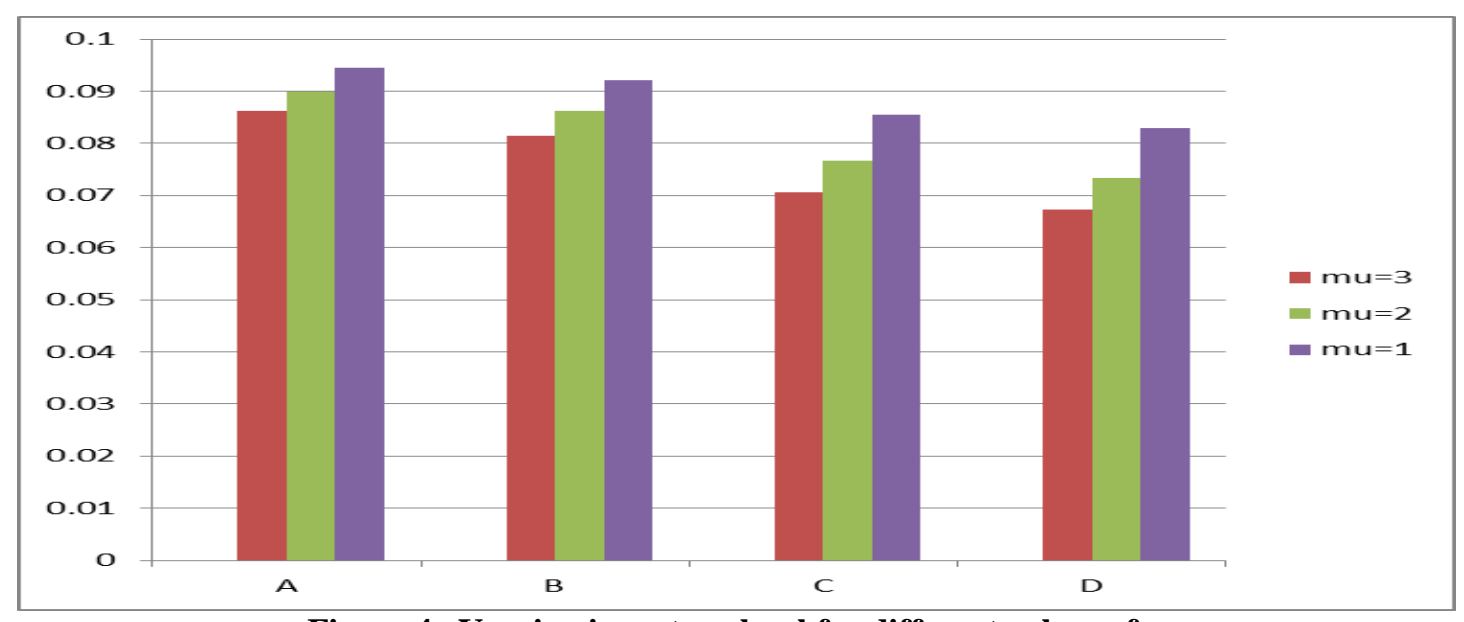

Figure 4. Varying inventory level for different values of $\mu$

In all scenarios inventory level is reduced by certain percentage by incorporating RFID. The inventory level reduction according to the different value of $\mu$ for all the four cases $\mathrm{A}, \mathrm{B}, \mathrm{C}$ and $\mathrm{D}$ is seen increasing as shown in the figure 4 above.

\section{Conclusion and Future Scope}

Even RFID technology has proven to be the most beneficial to industries in their supply chains, many industries don't dare to incorporate it on mass scale except some large scale industries like Wall-Mart. The industries are lacking in the knowledge of the methodology to calculate return on investment. The methodology discussed here in this text will provide the base to the industrial managers to recognize the benefits of RFID in supply chains and will encourage them to adopt on mass scale. The research in this area has tremendous scope as the technology is gaining attention world wide. We feel this work would benefit industries in achieving excellence in the material management incorporating RFID.

\section{References:}

[1] Rajurkar S., Jain R., Optimal order quantity model for retailers of perishable products with non-deterministic demand, International Journal of Operation Research, 11(3), 2011, 262 - 289.

[2] Hau L. Lee, V. Padmanabhan and Seungjin Whang, Information Distortion in a Supply Chain: The Bullwhip Effect, Management Science, 43(4), 1997, 546-558.

[3] Chopra S., Reinhardt G., Dada M., The Effect of Lead Time Uncertainty on Safety Stocks, Decision Sciences, 35(1), 2004, 1-24. 
[4] Jing-Sheng S., The Effect of Lead time Uncertainty in a Simple Stochastic Inventory Model, Management Science, 40( 5), 1994, $603-613$.

[5] Xiaojing W., Zhixue L., Changzheng Z., Chunguang Q., The Impact of Lead-time on Bullwhip Effect in Supply Chain, IEEE Transactions, 2008.

[6] Roger D. H. W., An Analytical Investigation of the Bullwhip Effect, Production And Operations Management, 13(2), 2004, 150160 .

[7] Brzozowski, C., Tags, tickets \& labels: new technologies emerge, Printing News, 153(3), 2004.

[8] Glidden, R. and Bockorick, C.,Design of ultralow- cost UHF RFID tags for supply chain applications, IEEE Communications Magazine, 42(8), 2004, 140-151.

[9] Knights, P.F., Henderson, E. and Daneshmend, L.K., Drawpoint control using radio frequency identification systems, CIM Bulletin, 89 (1003), 2004, 53-58.

[10] Wilke, P. and Braunl, T., Flexible wireless communication network for mobile robot agents, Industrial Robot, 28 (3), 2001, 220233.

[11] Ashley S., Penny-wise smart labels, Scientific American, 291(2) , 2004, 30-41.

[12] Leslee N. H. and Tim C., RFID Opportunities and Risks, The Journal of Corporate Accounting \& Finance, $2006,51-57$.

[13] Alp Ustundag, Mehmet S. K., Emre C., Fuzzy rule-based system for the economic analysis of RFID investments, Expert Systems with Applications, 37, 5300-5306, 2010.

[14] P.M. Ghare, G.F. Shrader, A Model for exponentially decaying inventories, Journal of Industrial Engineering, 14, $238-243,1963$.

[15] R.P. Covert, G.C. Philip, An EOQ model for items with Weibull distribution deterioration, American Institute of Industrial Engineering Transaction, 5, 1973, 323-326.

[16] Y.K. Shah, An order-level lot-size inventory for deteriorating items, American Institute of Industrial Engineering Transaction, 9 , 1977, 108-112.

[17] U. Dave, L.K. Patel, (T,Si) policy inventory model for deteriorating items with time proportional demand, Journal of Operation Research Society, 32, 1984, 1013-1019.

[18] R.S. Sachan, On (T,Si) inventory policy model for deteriorating items with time proportional demand, Journal of Operation Research Society, 35, 1984, 1013-1019.

[19] T.K. Datta, A.K. Pal, Order level inventory system with power demand pattern for items with variables rate of deterioration, Indian Journal of Pure and Applied Mathematics, 19, 1988, 1043-1053.

[20] A. Goswami, K.S. Glaudhuri, An EOQ model for deteriorating items with shortages and a linear trend in demand, Journal of Operation Research Society, 42, 1991, 1105-1110.

[21] J.T. Teng, M.C. Chem, H.L. Yang, Y.J. Wang, Deterministic lot size inventory models with shortages and deterioration for fluctuating demand, Operation Research Letter, 24, 1999, 65-72.

[22] K. Skouri, S. Papachristos, A continuous review inventory model, with deteriorating items, time-varying demand, linear replenishment cost, partially time-varying backlogging, Applied Mathematical Modelling, 26, 2002, 603-617.

[23] A.K. Bhunia, M. Maiti, An inventory model of deteriorating items with lot-size dependent replenishment cost and a linear trend in demand, Appl. Math. Model, 23, 301-308, 1999.

[24] Chung-Yuan Dye, Tsu-Pang Hsieh, Liang-Yuh Ouyang, Determining optimal. selling price and lot size with a varying rate of deterioration and exponential partial Backlogging, European Journal of Operational Research, 181, 668-678, 2007.

[25] Ek Peng Chew, Chulung Lee, Rujing Liu, Joint inventory allocation and pricing decisions for perishable products, International Journal of Production Economics, 120, 139-150, 2009.

[26] Paul G. Ranky, An introduction to radio frequency identification (RFID) methods and solution, Assembly Automation, 26 (1), 2833, 2006.

[27] Peter Jones, Colin Clarke-Hill, David Hillier and Daphne Comfort, The benefits, challenges and impacts of radio frequency identification technology (RFID) for retailers in the UK, Marketing Intelligence \& Planning, 23 (4), $2005395-402$.

[28] Eleonora Bottani, Roberto Montanari, Andrea Volpi, The impact of RFID and EPC network on the bullwhip effect in the Italian FMCG supply chain, Int. J. Production Economics, 124, 426-432, 2010.

[29] James Jungbae Roh, Anand Kunnathur, Monideepa Tarafdar, Classification of RFID adoption: An expected benefits approach, Information \& Management, 46, 2009 357-363.

[30] Shiou-Fen Tzeng, Wun-Hwa Chen, Fan-Yun Pai, Evaluating the business value of RFID: Evidence from five case studies, Int. J. Production Economics, 112, 2008, 601-613.

[31] In Lee, Byoung-Chan Lee An investment evaluation of supply chain RFID technologies: A normative modeling approach, International Journal of Production Economics, 2010, 125.

[32] Chaug-Ing Hsu , Hsien-Hung Shih, Wei-Che Wan, Applying RFID to reduce delay in import cargo customs clearance process, Computers \& Industrial Engineering, 57, 2009, 506-519.

[33] A.G. de Kok, K.H. van Donselaar, T. van Woensel, A break-even analysis of RFID technology for inventory sensitive to shrinkage, Int. J. Production Economics, 112, 2008, 521-531.

[34] N.C. Wu, M.A. Nystrom, T.R. Lin, H.C. Yu, Challenges to global. RFID adoption, Technovation, 2005.

[35] Roberto Di Pietro, Refik Molva, Optimal probabilistic solution for information confinement, privacy, and security in RFID systems, Journal of Network and Computer Applications, 2010.

[36] Eun-Kyung Ryu, Tsuyoshi Takagi, A hybrid approach for privacy-preserving RFID tags, Computer Standards \& Interfaces, 31, 2009, 812-815.

[37] Estrada-Flores S, Tanner DJ, Amos ND., Cold chain management during transport of perishable products, Food Australia, 54 (7), 2002, 268-270.

[38] Jedermann R, Lang W., Semi-passive RFID and beyond: steps towards automated quality tracing in the food chain. Int. J. Radio Frequency Identification Technology and Applications, 1(3), 2007, 247-259. 